\title{
The use of reflectance measurements in the determination of fixation of reactive dyes to cotton
}

\section{Document Version}

Accepted author manuscript

Link to publication record in Manchester Research Explorer

\section{Citation for published version (APA):}

Ahmed, N., Oulton, D. P., \& Taylor, J. A. (2006). The use of reflectance measurements in the determination of fixation of reactive dyes to cotton. Color Research and Application, 31(2), 117-121.

\section{Published in:}

Color Research and Application

\section{Citing this paper}

Please note that where the full-text provided on Manchester Research Explorer is the Author Accepted Manuscript or Proof version this may differ from the final Published version. If citing, it is advised that you check and use the publisher's definitive version.

\section{General rights}

Copyright and moral rights for the publications made accessible in the Research Explorer are retained by the authors and/or other copyright owners and it is a condition of accessing publications that users recognise and abide by the legal requirements associated with these rights.

\section{Takedown policy}

If you believe that this document breaches copyright please refer to the University of Manchester's Takedown Procedures [http://man.ac.uk/04Y6Bo] or contact uml.scholarlycommunications@manchester.ac.uk providing relevant details, so we can investigate your claim.

\section{OPEN ACCESS}




\section{The Use of Reflectance Measurements in the Determination of Fixation of Reactive Dyes to Cotton}

\section{N. Ahmed, D. P. Oulton, J. A. Taylor*}

Textile sand Paper Group, School of Materials, University of Manchester, P.O. Box 88, Sackville Street, Manchester M60 1QD, United Kingdom

Received 3 January 2005; accepted 9 August 2005

Abstract: The utility of the Kubelka-Munk equation for determining the fixation of reactive dyes to cotton has been assessed. Large $\mathrm{K} / \mathrm{S}$ values are not linearly related to dye concentration on fabric and thus give an inaccurate assessment of fixed dye. If lower values of K/S are selected, by measuring at a suitable wavelength, a linear relationship exists with the concentration of dye present, even at very heavy depths of shade. Thus, by judicious choice of wavelength, K/S values can provide an accurate and convenient method for the assessment of dye on fabric, provided that a reference fabric sample, with a known concentration of the same dye, is available as a standard for comparison. Significant implications are then revealed for construction scalable models of opaque medium reflectance that are homogeneously linear over wavelength with respect to colorant concentration change. (C) 2006 Wiley Periodicals, Inc. Col Res Appl, 31, 117-121, 2006; Published online in Wiley InterScience (www. interscience.wiley.com). DOI 10.1002/col.20189

Key words: colour modeling; scalable functions; KubulkaMunk; dye fixation; reactive dyes

\section{INTRODUCTION}

The light absorption of a solute in solution obeys the Beer Lambert law, that is, the absorbance of the solution at a given wavelength has a constant, linear functional relationship to the concentration of the absorbing species. At higher loadings of a solute, such as a dye, divergence from the Beer-Lambert law is often observed: this is sometimes taken as evidence of aggregation. Optical density (OD) is typically

\footnotetext{
*Correspondence to: J. A. Taylor (e-mail: John.A.Taylor@manchester. ac.uk)
}

used to linearize the relationship with the light transmittance, $T$, and it is defined such that at a given wavelength $l$.

$$
\mathrm{OD}=-\log T
$$

where $T$ is the decimal transmittance in transparent media and

$$
\mathrm{OD}_{\lambda}=k_{\lambda} \cdot C \cdot L,
$$

where $k_{\lambda}$ is the absorption coefficient, $C$ is the molar concentration of the solute, and $L$ is the path length in centimeters.

Optical density is therefore what is described by Berns ${ }^{1}$ as a "scalable function." That is to say, it creates a strictly linear model of the monochromatic light absorption effect of colorants in transparent media that is independent of wavelength. The appropriate function is fully scalable, if the calibrated nonlinearity relative to $T$ has an identical functional form at all wavelengths as in the current example, where the logarithmic transformation works well at all wavelengths. OD is in general regarded as fully scalable, and partial OD values measured at multiple wavelengths can thus be used to determine the individual concentrations of mixed solutes using simultaneous linear equations.

In opaque media Beer Lambert's law is not applicable and the Kubelka-Munk theory has been widely applied to describe the depth of colour of, for example, a dye on a textile substrate. This has proved a valuable tool to dye users and dye manufacturers and has allowed an objective assessment of the depth of a particular shade of dye on textile substrates, as described by Derbyshire and Marshall. ${ }^{2}$ This has important commercial consequences; the dye house manager clearly must achieve a given shade at the lowest dye cost, consistent with the required fastness criteria being satisfied. 
$K / S$ values have also been used, at the wavelength of maximum absorption, to gain a quantitative assessment of the amount of dye on fabric. ${ }^{3}$ In our hands this has proved unreliable, especially at heavy depths of shade.

Other methods of measuring dye fixation include reduction of fixed dye by titanium (III) chloride on fabric. ${ }^{4}$ Here a piece of dyed fabric or fiber is treated with excess of a powerful reducing agent, such as titanium (III) chloride; this causes reduction of any azo or anthraquinone dyestuff attached to the fiber. The excess titanium (III) chloride remaining after reduction is back-titrated against a dye of accurately known strength. The quantity of titanium III chloride required for the reduction of the fixed dye is thus obtained by difference, and therefore the concentration of the fixed dye can be calculated. This method is limited to coloured materials that are reduced rapidly and efficiently with titanium (III) chloride.

The dissolution of dyed cotton in $70 \%$ sulfuric acid and subsequent spectrophotometric assessment of the amount of dye in the resulting solution has also proved a useful technique. ${ }^{4}$ This has been particularly effective on cellulosic fibers, such as lyocell and cotton, which dissolve rapidly in sulfuric acid, but the method is limited to those chromophores that are stable in this solvent.

Finally, investigators have routinely collected all of the dyebath and dye wash liquors and assessed the amount of the unfixed dye spectrophotometrically, with the amount of fixed dye being obtained by difference. ${ }^{5}$ This method can be particularly time consuming, but is capable of providing quantitative information on the amount of loose dye removed during each washing.

In the following account, the scalability of the simple Kubelka-Munk (theoretical) function at wavelength $\lambda$ is examined, where

$$
(K / S)_{l}=\left(1-R_{\lambda}\right)^{2} / 2 R_{\lambda}
$$

and $K$ is the light absorption coefficient, $S$ is the light scattering coefficient, and $R_{\lambda}$ is the decimal reflectance of an infinite thickness of dyed fabric.

(An alternative form of the Kubelka-Munk equation is sometimes used:

$$
\begin{aligned}
K / S=\left[\left(1-\left(R_{c}-R_{s}\right)\right)^{2} / 2\left(R_{c}-R_{s}\right)\right] & \\
- & {\left[\left(1-\left(R_{0}-R_{s}\right)\right)^{2} / 2\left(R_{0}-R_{s}\right)\right], }
\end{aligned}
$$

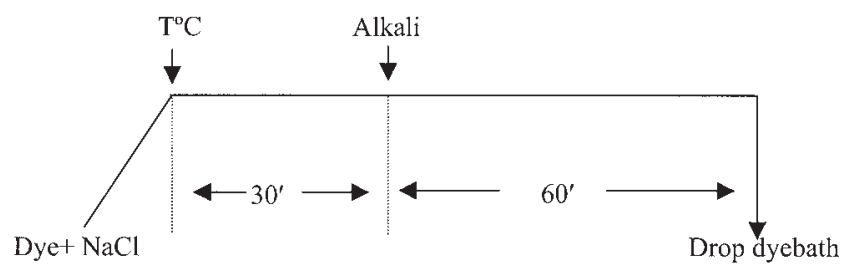

Wash off
TABLE I. Auxiliary requirements for dyeing with Levafix Navy Blue E-BNA and Procion Navy H-ER.

\begin{tabular}{ccc}
\hline $\begin{array}{c}\text { Dye on mass } \\
\text { of fabric }(\%)\end{array}$ & $\begin{array}{c}\text { Salt concentration } \\
(\mathrm{g} / \mathrm{l})\end{array}$ & $\begin{array}{c}\text { Soda ash concentration } \\
(\mathrm{g} / \mathrm{l})\end{array}$ \\
\hline & & \\
2 & 40 & 15 \\
4 & 50 & 20 \\
6 & 60 & 25 \\
9 & 80 & 25 \\
& 80 & 25 \\
\hline
\end{tabular}

where $K$ = coefficient of light sorption, $S=$ coefficient of light scattering, $R_{c}=$ reflectance at the wavelength minimum reflectance of a substrate containing $C$ concentration of dye, $R_{s}=$ surface reflectance, i.e., the reflectance at the same wavelength as above of a substrate containing an "infinite" amount of dye. Surface reflectance is the minimum reflectance value that can be obtained on a given substrate. $R_{0}=$ reflectance at the same wavelength as above of a substrate that has been subjected to a dyeing process in the absence of dye, so-called mock dyeing.)

\section{EXPERIMENTAL PROCEDURES}

Scoured, knitted, bleached $100 \%$ cotton fabric was used for all experiments. Five-gram pieces of fabric were used for each dyeing and each was weighed to an accuracy of $0.01 \mathrm{~g}$. Reactive dyes were applied according to the manufacturers' instructions. Each was dyed at five depths of shade, namely 1, 2, 4, 6, and 9\% of dye on mass of fabric (omf). All dyeings were conducted using a Mathis Labomat RotaDyer, type Nr BFA 1289997 having 12 tubes; each tube was of 200-ml capacity. All dyeings were carried out at a liquor ratio of 10:1 using the dyeing cycle depicted in Fig. 1. Three different dyes were evaluated: Remazol Black B, Levafix Navy Blue E-BNA, and Procion Navy H-ER.

The Levafix dye was applied at $40^{\circ} \mathrm{C}$, the Remazol at $60^{\circ} \mathrm{C}$, and the Procion dye at $80^{\circ} \mathrm{C}$. The alkali and salt contents for the Levafix and Procion dyes were identical and are displayed in Table I; the corresponding values for the Remazol dye are displayed in Table II.

The $(K / S)_{1}$ (simple theoretical form) values were measured using a Datacolor International Spectroflash 600 spectrophotometer. The instrument was calibrated using black and white tiles and the maximum aperture size was used for all measurements. Each $K / S$ value was recorded on a piece of fabric that had been folded over twice, so as to provide

TABLE II. Auxiliary requirements for dyeing with Remazol Black B.

\begin{tabular}{ccc}
\hline $\begin{array}{c}\text { Dye on mass of fabric } \\
(\%)\end{array}$ & $\begin{array}{c}\text { Salt concentration } \\
(\mathrm{g} / \mathrm{l})\end{array}$ & $\begin{array}{c}\text { Sodium hydroxide } \\
\text { concentration }(\mathrm{g} / \mathrm{l})\end{array}$ \\
\hline 1 & 50 & 0.9 \\
2 & 50 & 1.1 \\
4 & 50 & 1.5 \\
6 & 80 & 1.8 \\
9 & 80 & 1.8 \\
\hline
\end{tabular}


TABLE III. Fixation efficiencies of dyes by sulfuric acid dissolution of dyed fabric.

\begin{tabular}{cccc}
\hline & \multicolumn{3}{c}{$\%$ Dye fixed } \\
\cline { 2 - 4 } $\begin{array}{c}\text { Dye applied \% } \\
\text { (owf) }\end{array}$ & $\begin{array}{c}\text { Levafix Navy } \\
\text { Blue E-BNA }\end{array}$ & $\begin{array}{c}\text { Procion Navy } \\
\text { H-ER }\end{array}$ & $\begin{array}{c}\text { Remazol } \\
\text { Black B }\end{array}$ \\
\hline & 94.07 & 86.90 & 76.83 \\
2 & 93.34 & 79.76 & 74.18 \\
4 & 88.76 & 77.98 & 72.79 \\
6 & 83.21 & 72.02 & 70.01 \\
9 & 72.04 & 68.12 & 65.20 \\
\hline
\end{tabular}

four layers of fabric, and each determination was carried out three times.

Dye fixation was assessed by dissolving an accurately weighed piece of dyed fabric (ca. $0.03 \mathrm{~g}$ ) in $70 \%$ sulfuric acid $(50 \mathrm{ml})$. Each experiment was again carried out in triplicate. The optical density of the resulting solution was measured using a Philips PU 8700 series UV-visible spectrophotometer and 1-cm cells. This optical density was compared with that of a known weight of dye in a known volume of sulfuric acid, in order to obtain the exact concentration of colour on known weight of fabric. With this information the percentage of fixation of dye to fabric was readily determined. In the case of each dye a graph of absorbance against concentration of dye, in $70 \%$ sulfuric acid, was a straight line, confirming adherence to Beer Lambert's law. Additionally, the absorbance of each solution remained unchanged over $8 \mathrm{~h}$, demonstrating that the dye chromophores were adequately stable in sulfuric acid solution.

\section{RESULTS AND DISCUSSION}

Using the method described the fixation efficiencies of the dyes were determined and these are listed in Table III.

With all of the dyes a reduction in fixation efficiency was observed with increasing concentration of dye applied. This probably results largely from increased electrostatic repulsion between fixed and unfixed dye: as more dye fixes the net anionic character of the fabric increases, thus impeding approach, and therefore fixation, of further dye. Also, the number of effective available sites on the fabric is reduced with increasing concentration of fixed dye.

$K / S$ values, at the wavelength of maximum absorbance $\left(\lambda_{\max }\right)$, that is at the reflectance minimum, are used conventionally to describe the buildup behavior of dyes on textile substrates. For each of the three dyes $\lambda_{\max }$ lay between 600 and $610 \mathrm{~nm}$. Therefore, the $K / S$ of each of the dyes was recorded at $600 \mathrm{~nm}$. Results are listed in Table IV.

It can be seen that, under the dyeing conditions employed, the order of fixation efficiency is Levafix Navy Blue E-BNA > Procion Navy H-ER > Remazol Black B. However the Procion dye appears much weaker than the others, as judged by $K / S$ values

If a graph is plotted of $K / S$ at $\lambda_{\max }$ against concentration of fixed dye, at pale depths of shade $(K / \mathrm{S})_{\max }$ appears be a linear function of concentration of fixed dye, but the relationship deviates markedly from linearity at heavier load-
TABLE IV. Build up of dyes as assessed by K/S at $600 \mathrm{~nm}$.

\begin{tabular}{cccc}
\hline \multirow{2}{*}{$\begin{array}{c}\text { Dye } \\
\text { concentration } \\
(\%)\end{array}$} & $\begin{array}{c}\text { Kemazol } \\
\text { Black B }\end{array}$ & $\begin{array}{c}\text { Levafix Navy } \\
\text { Blue E-BNA }\end{array}$ & $\begin{array}{c}\text { Procion Navy } \\
\text { H-ER }\end{array}$ \\
\cline { 2 - 4 } & 11.59 & 12.25 & 5.80 \\
1 & 21.88 & 23.52 & 11.77 \\
2 & 31.68 & 34.84 & 20.50 \\
4 & 35.97 & 38.15 & 27.03 \\
6 & 37.85 & 38.44 & 31.68 \\
\hline
\end{tabular}

ings of dye and is better described by the fitted polynomial function of Eq. (5) $\left(R^{2}>0.99\right)$ (Fig. 2).

$$
\begin{aligned}
y & =-1.3045 x^{2}+13.56 x+3.0112 \\
R^{2} & =0.9904
\end{aligned}
$$

A similar situation is obtained for each of the two other dyes, Levafix Navy Blue E-BNA and Procion Navy H-ER.

However, if the graph of fixed dye concentration (as revealed by absorptiometry of dissolved fabric) is plotted against $K / S$ at different wavelengths, where $K / S$ is numerically smaller, a much better straight line fit is obtained. This is typified in Fig. 3.

In this case the correlation coefficient, $R^{2}$, is close to unity, signifying that, at this wavelength, the $K / S$ value is indeed directly proportional to concentration of fixed dye. Graphs were plotted, at every $50 \mathrm{~nm}$ wavelength, of $(K / S)_{\lambda}$ against concentration of dye and in each case the correlation coefficient was noted. In the case of Remazol Black B the figures are listed in Table V.

This table also lists the range of $(K / S)_{\lambda}$ values used to acquire the $R^{2}$ values; thus, $R^{2}$ values greater than 0.995 were obtained at $400,450,500$, and $700 \mathrm{~nm}$. These wavelengths covered a range of $K / S$ values from $0.83(700 \mathrm{~nm})$ to $26.27(500 \mathrm{~nm})$. Indeed, the best straight line fit appeared at $700 \mathrm{~nm}$, where the $K / S$ values were very low, ranging from 0.83 at $1 \%$ dye omf to 5.21 at $9 \%$ dye omf.

\section{Remazol Black B at $600 \mathrm{~nm}$}

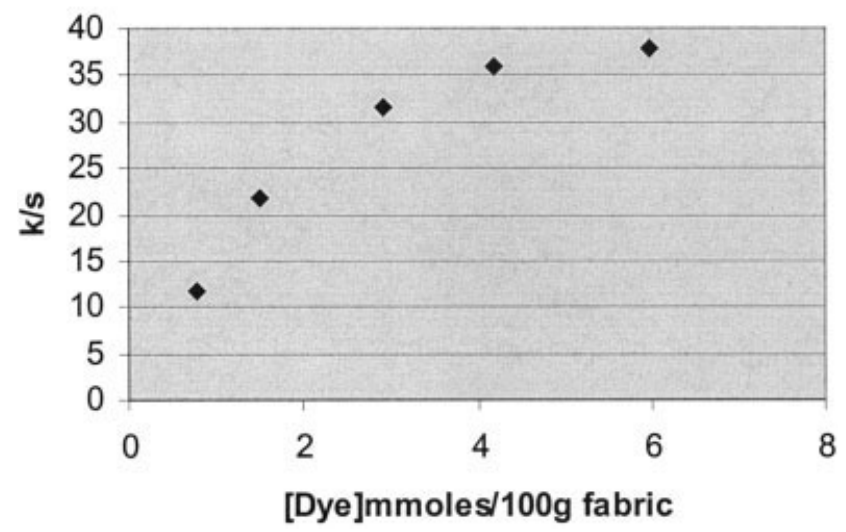

FIG. 2 Variation in $K / S$ with concentration of fixed dye at $600 \mathrm{~nm}$. 


\section{Remazol Black B at $700 \mathrm{~nm}$}

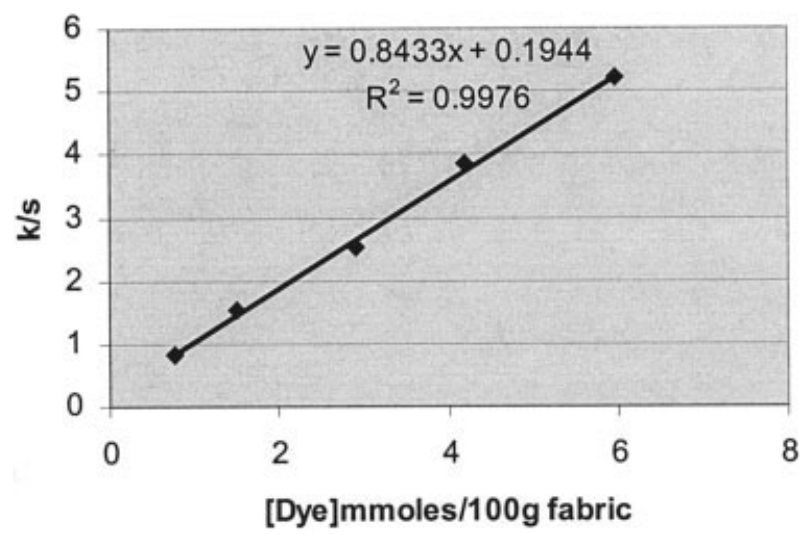

FIG. 3 Variation in $K / S$ with concentration of fixed dye at $700 \mathrm{~nm}$.

The other two dyes gave equally impressive straight line fits of $K / S$ versus concentration of fixed dye at appropriate wavelengths (Tables VI and VII).

As with Remazol Black B, graphs of $K / S$ (at $600 \mathrm{~nm}$ ) against dye concentration did not yield a straight line relationship either for Levafix Navy Blue E-BNA or for Procion Navy H-ER. At higher concentrations of fixed dye the $K / S$ value in each case gave an underestimate of the amount of dye present.

In the case of Levafix Navy Blue E-BNA, $R^{2}$ values greater than 0.999 were obtained at wavelengths 450 and $500 \mathrm{~nm}$. At $700 \mathrm{~nm}$ an $R^{2}$ value of 0.9989 was obtained for the Procion dye; the optimum straight line fits were again obtained at 400 , 450, 500, and $700 \mathrm{~nm}$. Thus, in general, we observe that the $K / S$ values measured in this experiment became significantly nonlinear with respect to concentration at $K / S>28$.

From the data shown in Tables V, VI, and VII, it can be seen that $K / S$ is directly proportional to concentration of fixed dye, if appropriate wavelengths and $K / S$ values are selected. It is interesting that, even at $700 \mathrm{~nm}$, where the amount of light absorption is relatively small, an excellent agreement is obtained.

\section{DISCUSSION}

It is clear from the above results that the Kubelka-Munk function is not scalable, in the sense that it is not a linearization function that generates absorbance factors $(K / S)_{\lambda}$

TABLE V. Correlation coefficients and $K / S$ values for Remazol Black B.

\begin{tabular}{clc}
\hline $\begin{array}{c}\text { Remazol Black B } \\
(\mathrm{nm})\end{array}$ & \multicolumn{1}{c}{$R^{2}$} & K/S range \\
\hline 400 & 0.9954 & $3.86-4.56$ \\
450 & 0.9971 & $3.26-23.21$ \\
500 & 0.9958 & $3.77-26.27$ \\
600 & 0.849 & $11.59-37.85$ \\
650 & 0.9324 & $6.4-30.6$ \\
700 & 0.9976 & $0.83-5.21$ \\
\hline
\end{tabular}

TABLE VI. Correlation coefficients and $K / S$ values for Levafix Navy Blue E-BNA.

\begin{tabular}{ccc}
$\begin{array}{c}\text { Remazol Black B } \\
(\mathrm{nm})\end{array}$ & $R^{2}$ & \\
\hline & & $K / S$ range \\
400 & 0.9993 & $2.83-5.63$ \\
450 & 0.9999 & $2.62-18.43$ \\
500 & 0.9994 & $3.06-21.81$ \\
550 & 0.9698 & $6.76-36.27$ \\
600 & 0.8377 & $12.25-38.44$ \\
650 & 0.9168 & $7.17-30.25$ \\
700 & 0.9989 & $0.64-3.53$ \\
\hline
\end{tabular}

that are linear constants for a given solute. This is well known in the field of computer match prediction, where iterative convergence is used to predict the reflectance values for dye recipes with multiple absorbing colorants. The relevant algorithms are described by Allen ${ }^{6}$ and McDonald. ${ }^{7}$

Full scalability is, however, not required when we wish to predict the concentration of a single colorant in the dyed fabric. In this case it is sufficient only to demonstrate strict linearization at a single wavelength for each of the single solute dyeings that are to be compared.

It is clear from the above results that for the three dyes being compared, strict linearization can only be demonstrated at wavelengths where $(K / S)_{\lambda}$ values are significantly lower than those at $\lambda_{\max }$.

Derbyshire and Marshall $^{2}$ demonstrate that a key problem with the Kubelka-Munk function is the asymptotic reflectance value $R_{0}$, that is, the minimum reflectance value $R_{\lambda}$ that is theoretically reached at infinite solute concentration. They thus propose a modified Kubelka-Munk function that gives improved scalability, such that

$$
\text { Integ }(K / S)_{1}=\left(1-R_{1}-R_{0}\right)^{2} / 2\left(R_{1}-R_{0}\right) .
$$

The Integ $(K / S)_{1}$ values thus calculated are then demonstrated to model standard depth successfully and have been used to predict the important property of tinctorial value when comparing the relative cost of individual dyes.

While Integ $(K / S)_{1}$ values can provide a somewhat improved method (relative to $K / S$ ) for the assessment of perceived visual depth of, for example, a particular dyeing on a textile, their relationship to concentration of fixed dye also deviates from linearity, especially at heavy depths. For a more accurate determination of dye concentration we recommend the rather simpler approach of choosing a wavelength at which the un-

TABLE VII. Correlation coefficients and $K / S$ values for Procion Navy H-ER.

\begin{tabular}{ccc}
$\begin{array}{c}\text { Remazol Black B } \\
(\mathrm{nm})\end{array}$ & $R^{2}$ & K/S range \\
\hline & 0.9988 & $1.66-11.37$ \\
400 & 0.9969 & $1.63-12.27$ \\
450 & 0.9983 & $2.16-15.61$ \\
500 & 0.9804 & $3.86-26.07$ \\
600 & 0.9637 & $5.8-31.68$ \\
650 & 0.9794 & $4.42-25.77$ \\
700 & 0.9968 & $0.64-3.73$ \\
\hline
\end{tabular}


modified Kubelka-Munk $(K / S)_{1}$ values are demonstrably linear as a function of solute concentration.

It is, however, very important to demonstrate strict linearity versus dye concentration, before definitive differences in dye fixation value are quoted. In principle, this requires that the actual concentration should be quantified by independent experiment such as sulfuric acid dilution (as in the above experiment). However, it may eventually prove possible to establish a general rule for the use of $(K / S)_{1}$ values as a linear function of concentration. For example, consulting Tables V-VII above $(K / S)_{1}$ values ranging up to say 25 may always be linear as a function of concentration.

\section{CONCLUSIONS}

The use of $(K / S)_{\max }$ to determine the amount of fixed dye on fabric is unreliable at heavy depths of shade. If lower values of $K / S$ are used, by selection of an appropriate wavelength, the method provides an accurate indication of the amount of fixed dye, provided that the relationship of $K / S$ to concentration of dye is known for a single loading of dye.

1. Berns RS. A generic approach to color modeling. Color Res Appl 1997;22:318-325.

2. Derbyshire AN, Marshall WJ. Value analysis of dyes - a new method based on colour measurement. J Soc Dyers 1980;96:166-177.

3. Burkinshaw SM, Wills AE. The dyeing of conventional and microfibre nylon 6.6 with reactive dyes. Dyes Pig 1997;34:243-253.

4. Murtagh V, Taylor JA. A simple titrimetric method for the estimation of reactive dye fixation on cellulose. Dyes Pig 2004;63:17-22.

5. Lewis DM, Ho YC. Improved fixation of dyes on polyamide fibres. Dyes Pig 1996;31:111-129.

6. Allen E. Basic equations used in computer colour matching. J Opt Soc Am 1966;56:1256-1259.

7. McDonald R. Recipe prediction for textiles. In: Colour physics for industry. 2nd ed. Publ. Society of Dyers and Colourists: Bradford, UK; 1997. p 209-291. 